Vegetalika Vol. 10 No. 1, Februari 2021:18-30 Available online at https://jurnal.ugm.ac.id/jbp DOI: https://doi.org/10.22146/veg.57787 p-ISSN: 2302-4054 | e-ISSN: 2622-7452

\title{
Hubungan Nisbah Perakaran Dalam dengan Ketahanan Kekeringan dan Hasil Enam Kultivar Padi (Oryza Sativa L.)
}

\section{Relationship Between Deep Rooting Ratio, Drought Tolerance, and Yields of Six Rice Cultivars (Oryza sativa L.)}

\author{
Ahmad Zainal Abidin, Didik Indradewa* \\ Departemen Budidaya Pertanian, Fakultas Pertanian, Universitas Gadjah Mada \\ Jalan Flora No. 1, Bulaksumur, Sleman, Yogyakarta 55281, Indonesia \\ *) Penulis untuk korespodensi E-mail: didikindradewa54@yahoo.com
}

Diajukan: 13 Juli 2020 /Diterima: 15 Februari 2021 /Dipublikasi: 26 Februari 2021

\begin{abstract}
Rice is an important commodity with the increasing in demand every year. Expansion of the planting area to a dry land is one way to increase rice production. Research on drought resistance in rice is needed. The purpose of the study was to determine the characters of rooting in the form of the ratio of the amount, fresh weight, dry weight, length, surface area, and volume of deeper roots that have a relationship with drought resistance in upland rice plants. The study was held in Kebun Tridharma Fakultas Pertanian, Universitas Gadjah Mada in Banguntapan, Bantul, Yogyakarta from March until August 2019. Experimental design used was split plot with two factors (drought treatment as the first factor and cultivar as the second factor). Rice cultivars used in this research were Unsoed Parimas, Rindang 2, Inpago 9, Inpago 10, Inpago 11 and IR 64. The drought treatments consisted of two levels, enough water which was watered every two days and drought stress which was watered every ten days. Observation variabels were deep rooting ratio (root numbers, root fresh weight, root dry weight, root length, root surface, root volume) and stress tolerance index. The results showed that there were significant positive relationship between the deep-rooting dry weight ratio, deep-rooting length ratio, and deep-rooting surface area with stress tolerance index of yield at harvest. The deep-rooting ratio could not be used as early estimate drought resistance of rice plants at 6 and 9 weeks.
\end{abstract}

Keywords: deep rooting ratio; drought; rice; tolerance

\section{INTISARI}

Padi merupakan komoditas penting yang mengalami peningkatan kebutuhan tiap tahun. Perluasan areal penanaman ke lahan kering adalah salah satu cara meningkatkan produksi padi. Perlu penelitian terhadap ketahanan kekeringan pada padi agar kebutuhan dapat terpenuhi. Tujuan dari penelitian ini adalah menentukan nisbah jumlah, bobot segar, bobot kering, panjang, luas permukaan, dan volume perakaran dalam yang mempunyai hubungan dengan ketahanan kekeringan pada tanaman padi gogo secara dini. Penelitian ini dilakukan di Kebun Tridharma Fakultas Pertanian, Universitas Gadjah Mada di Banguntapan, Bantul, Yogyakarta pada bulan Maret sampai Agustus 2019. Rancangan lingkungan yang dipakai split plot dengan dua faktor yaitu perlakuan kekeringan sebagai faktor pertama dan kultivar sebagai faktor kedua. Perlakuan kekeringan terdiri dari 2 aras yaitu cukup air dengan disiram 2 hari sekali dan kekeringan dengan disiram 10 hari sekali. Kultivar padi yang digunakan terdiri dari 6 macam yaitu Unsoed Parimas, Rindang 2, Inpago 9, Inpago 10, Inpago 11 dan IR 64. Variabel pengamatan berupa nisbah perakaran dalam (jumlah akar, bobot segar akar, bobot kering akar, panjang akar, luas permukaan akar, volume akar) dan indeks toleransi 
cekaman. Terdapat hubungan nyata nisbah bobot kering perakaran dalam, nisbah panjang perakaran dalam, dan nisbah luas permukaan perakaran dalam dengan indeks toleransi cekaman hasil saat panen. Nisbah perakaran dalam tidak dapat digunakan untuk pendugaan ketahanan kekeringan tanaman padi secara dini, yaitu pada 6 mst dan 9 mst.

\section{Kata kunci: kekeringan; nisbah perakaran dalam; padi; toleransi}

\section{PENDAHULUAN}

Produksi beras tahun 2018 adalah sebesar 32,42 juta ton; sedangkan konsumsi beras di Indonesia dari Januari hingga Desember 2018 diperkirakan sekitar 29,57 juta ton; dengan demikian surplus produksi beras di Indonesia pada tahun 2018 diperkirakan sekitar 2,85 juta ton (Badan Pusat Statistik, 2018). Menurut Anonim et al. (2013), hasil proyeksi menunjukkan bahwa jumlah penduduk Indonesia selama dua puluh lima tahun mendatang terus meningkat yaitu dari 238,5 juta pada tahun 2010 menjadi 305,6 juta pada tahun 2035. Oleh karena itu, ketersediaan beras nasional harus tersedia dalam jumlah yang cukup bagi penduduk yang jumlahnya semakin meningkat. Peningkatan produksi beras nasional dapat diupayakan dengan cara ekstensifikasi pertanian. Ekstensifikasi pertanian adalah upaya peningkatan produksi hasil pertanian dengan memperluas lahan pertanian baru, misalnya dengan menggunakan lahan marjinal. Lahan kering merupakan sumber daya yang potensial untuk mempertahankan swasembada beras.

Faktor pembatas penggunaan lahan kering terutama di wilayah beriklim kering untuk budidaya tanaman adalah ketersediaan air yang sangat rendah. Selain itu, terdapat masalah tambahan yaitu kekeringan yang disebabkan oleh perubahan iklim. Perubahan iklim menjadi salah satu penyebab terjadinya kekeringan yang dapat mengurangi hasil dan kualitas hasil padi yang rentan kekurangan air (Tao et al., 2006). Padi gogo merupakan tanaman padi yang dapat ditanam pada lahan kering. Daerah kering mempunyai ketersediaan air yang terbatas, sehingga padi gogo yang ditanam di daerah kering harus mempunyai sifat toleran terhadap kekeringan (Purwono dan Purwanti, 2007).

Perakaran tanaman memiliki peran penting dalam penyerapan dan translokasi untuk air dan nutrisi bagi tanaman. Karakter tanaman yang adaptif terhadap kekeringan di antaranya sistem perakaran tanaman yang baik, misalnya memiliki distribusi yang mengumpul pada bagian lapisan olah tanah, tetapi memiliki kemampuan penetrasi yang lebih dalam (Comas et al., 2013).

Partisi asimilat yang lebih banyak ke arah akar merupakan respon tanaman terhadap cekaman kekurangan air. Asimilat tersebut digunakan untuk memperluas sistem perakaran dalam memenuhi kebutuhan transpirasi di bagian atas tanaman. Mekanisme morfofisiologis tanaman untuk menghindar dari cekaman kekeringan adalah dengan memanjangkan akarnya untuk mencari sumber air yang relatif jauh dari permukaan tanah pada saat terjadi cekaman kekeringan (Abdullah et al., 2010). Perakaran yang dalam dan padat berpengaruh terhadap penyerapan air dengan besarnya tempat penampungan air tanah (Mackill et al., 1996). Menurut Yoshida dan Hasegawa (1982) dalam Uga et al. (2011) sistem akar dalam dianggap memungkinkan tanaman untuk menghindari tekanan kekeringan dengan 
menyerap air dari lapisan tanah yang dalam. Nisbah perakaran yang besar menunjukkan banyaknya jumlah akar yang tumbuh ke arah dalam dan bawah dibandingkan menyebar ke samping, hal ini menunjukkan tanaman beradaptasi dengan memanjangkan akar untuk terus tumbuh ke dalam sehingga akar mampu mencari sumber air ke dalam tanah.

Tujuan penelitian ini adalah menentukan nisbah jumlah, bobot segar, bobot kering, panjang, luas permukaan, dan volume perakaran dalam yang mempunyai hubungan dengan ketahanan kekeringan pada tanaman padi gogo secara yaitu pada umur 6 mst dan 9 mst.

\section{BAHAN DAN METODE}

Penelitian dimulai dari bulan Maret 2019 hingga Agustus 2019 di Kebun Tridharma Fakultas Pertanian, Universitas Gadjah Mada di Banguntapan, Bantul, Yogyakarta. Alat yang digunakan pada penelitian ini dikelompokkan menjadi dua, yaitu alat budidaya dan pengamatan. Alat budidaya antara lain keranjang plastik (bakul nasi) diameter $23 \mathrm{~cm}$, polibag, kain kasa, dan plastik UV. Alat pengamatan antara lain oven, timbangan analitik, thermohigrometer, alat tulis, leaf area meter serial no 380415220 V 50 Hz oleh DeltaT Devices LTD tingkat ketelitian $10.000 \mathrm{~mm}^{2}$, sprayer, dan label. Bahan yang diperlukan antara lain benih enam kultivar padi yang diperoleh dari Balai Besar Penelitian Padi dan Toko Pertanian yaitu Unsoed Parimas, Rindang 2, Inpago 9, Inpago 10, Inpago 11, dan IR 64, pupuk Urea, pupuk $\mathrm{KCl}$, pupuk SP36, media tanah, pupuk organik, dan pestisida.
Rancangan lingkungan yang digunakan berupa split plot dengan dua faktor yang diuji coba yaitu perlakuan kekeringan sebagai faktor pertama dan kultivar sebagai faktor kedua. Perlakuan kekeringan terdiri dari 2 aras yaitu cukup air dengan disiram 2 hari sekali dan kekeringan dengan disiram 10 hari sekali. Kultivar yang digunakan terdiri dari 6 macam kultivar padi yaitu Unsoed Parimas, Rindang 2, Inpago 9, Inpago 10, Inpago 11 dan IR 64. Terdapat blok sebagai ulangan dengan kombinasi perlakuan sebanyak 12 sehingga terdapat 48 unit percobaan. Setiap unit percobaan terdiri atas 4 polibag (3 polibag +1 polibag sulaman) yang secara keseluruhan terdiri dari 192 polibag. Korban diambil sebanyak tiga kali, yaitu pada saat fase vegetatif (umur $6 \mathrm{mst}$ ), fase generatif awal (umur $9 \mathrm{mst}$ ), dan saat panen. Variabel pengamatan antara lain, nisbah jumlah perakaran dalam, nisbah bobot segar perakaran dalam, nisbah bobot kering perakaran dalam, nisbah panjang perakaran dalam, nisbah luas permukaan perakaran dalam, nisbah volume perakaran dalam, dan indeks toleransi cekaman.

Nisbah perakaran dalam $=\frac{\text { Akar yang tumbuh keluar ke bawah }}{\text { akar total } \text { keluar }}$

Analisis data dilakukan menggunakan uji Annova, kemudian dilakukan uji Honest Significant Difference (Beda Nyata Terkecil) Tukey dengan taraf kepercayaan 95\%. Dilakukan uji Korelasi Indeks Toleransi Cekaman biji dan bobot kering dengan Nisbah Perakaran Dalam (jumlah, bobot segar, bobot kering, panjang, luas, volume). 


\section{HASIL DAN PEMBAHASAN}

Suhu udara mingguan $\left({ }^{\circ} \mathrm{C}\right)$ di lokasi penelitian yang bersifat fluktuatif setiap minggunya hingga minggu ke-15 dan kemudian mengalami kenaikan hingga minggu ke-19. Pengamatan suhu udara dilakukan 3 kali yaitu pada pagi hari (09.00), siang hari (12.00), dan sore hari (15.00) yang kemudian dirata-rata. Rata-rata suhu udara tertinggi terdapat pada minggu ke-19 $\left(37.7^{\circ} \mathrm{C}\right)$ sedangkan suhu udara terendah terdapat pada minggu ke-8 $\left(30,50^{\circ} \mathrm{C}\right)$. Suhu udara rata-rata selama pertumbuhan tanaman di lapangan yaitu $33,9^{\circ} \mathrm{C}$. Suhu optimal untuk penanaman padi adalah antara $25^{\circ} \mathrm{C}$ dan $35^{\circ} \mathrm{C}$ (Reyes et al., 2003), sehingga suhu udara saat penelitian sudah sesuai dengan syarat tumbuh tanaman padi. kelembaban udara di lokasi penelitian mengalami fluktuatif di setiap minggunya. Rata-rata kelembapan tertinggi terdapat pada minggu ke-8 dengan kelembapan $57 \%$ serta rata-rata kelembaban terendah terdapat pada minggu ke-14 dengan kelembapan $42 \%$. Kelembaban relatif optimal untuk penanaman padi terletak antara $60 \%$ dan $80 \%$
(Rathnayake et al., 2016), sedangkan kelembaban udara rata-rata saat penelitian terletak antara $42 \%$ dan $57 \%$ sehingga kurang sesuai bagi pertumbuhan optimal tanaman padi. Menurut Vijayakumar (1996), kelembaban relatif minimum yang diperlukan untuk pembungaan padi adalah $40 \%$, jika $\mathrm{RH}$ di bawah $40 \%$, pembungaan terhambat. Kelembaban minimum pada penelitian yaitu $42 \%$, sehingga pembungaan tidak terhambat.

Nisbah perakaran dalam adalah hasil perbandingan akar yang keluar mengarah ke bawah dengan total akar keluar dari keranjang. Pengamatan akar pada pendugaan nisbah perakaran dalam dapat dijadikan indikator tanaman mampu bertahan pada keadaan kering. Nisbah perakaran yang besar menunjukkan banyaknya akar yang tumbuh ke arah dalam dan bawah dibandingkan menyebar ke samping, hal ini menunjukkan tanaman beradaptasi dengan memanjangkan akar untuk terus tumbuh ke dalam sehingga akar mampu mencari sumber air ke dalam tanah

Tabel 1. Perakaran Total Antar Kultivar

\begin{tabular}{llllllllll}
\hline & \multicolumn{3}{c}{ BK Akar Total } & \multicolumn{3}{c}{ Pj Akar Total } & \multicolumn{3}{c}{ Luas Akar Total } \\
\cline { 2 - 9 } \multicolumn{1}{c}{ Kultivar } & $6 \mathrm{mst}$ & $9 \mathrm{mst}$ & Panen & $6 \mathrm{mst}$ & $9 \mathrm{mst}$ & Panen & $6 \mathrm{mst}$ & $9 \mathrm{mst}$ & Panen \\
\hline Unsoed P. & $1,46 \mathrm{a}$ & $4,86 \mathrm{a}$ & $8,23 \mathrm{ab}$ & $2304 \mathrm{a}$ & $7219 \mathrm{a}$ & $10114 \mathrm{ab}$ & $571 \mathrm{a}$ & $1503 \mathrm{a}$ & $1910 \mathrm{ab}$ \\
Rindang 2 & $1,16 \mathrm{a}$ & $4,18 \mathrm{a}$ & $12,02 \mathrm{a}$ & $1642 \mathrm{a}$ & $6185 \mathrm{a}$ & $14646 \mathrm{a}$ & $389 \mathrm{a}$ & $1281 \mathrm{a}$ & $2789 \mathrm{a}$ \\
Inpago 9 & $2,24 \mathrm{a}$ & $4,38 \mathrm{a}$ & $4,13 \mathrm{c}$ & $3087 \mathrm{a}$ & $6092 \mathrm{a}$ & $4615 \mathrm{c}$ & $823 \mathrm{a}$ & $1348 \mathrm{a}$ & $933 \mathrm{c}$ \\
Inpago 10 & $1,05 \mathrm{a}$ & $3,21 \mathrm{a}$ & $5,68 \mathrm{bc}$ & $1497 \mathrm{a}$ & $4875 \mathrm{a}$ & $7050 \mathrm{bc}$ & $342 \mathrm{a}$ & $1095 \mathrm{a}$ & $1301 \mathrm{bc}$ \\
Inpago 11 & $1,32 \mathrm{a}$ & $2,93 \mathrm{a}$ & $5,89 \mathrm{bc}$ & $1882 \mathrm{a}$ & $4526 \mathrm{a}$ & $7405 \mathrm{bc}$ & $441 \mathrm{a}$ & $937 \mathrm{a}$ & $1433 \mathrm{bc}$ \\
IR64 & $0,66 \mathrm{a}$ & $2,75 \mathrm{a}$ & $6,28 \mathrm{bc}$ & $998 \mathrm{a}$ & $4377 \mathrm{a}$ & $6390 \mathrm{bc}$ & $217 \mathrm{a}$ & $897 \mathrm{a}$ & $1231 \mathrm{bc}$ \\
\hline $\mathrm{CV}(\%)$ & 17,9 & 27,7 & 22,9 & 16,8 & 28,6 & 16,4 & 20,4 & 29 & 22,9 \\
\hline
\end{tabular}

Keterangan: Angka-angka diikuti oleh huruf sama pada kolom yang sama tidak berbeda nyata setelah dilakukan uji lanjut HSD Tukey dengan taraf kepercayaan 95\%. BK: Bobot Kering, Pj: Panjang, Luas: Luas Permukaan. 
Tabel 2. Perakaran Total pada Perbedaan Kondisi Lengas

\begin{tabular}{llllllllll}
\hline \multirow{2}{*}{ Kondisi Lengas } & \multicolumn{3}{c}{ BK Akar Total } & \multicolumn{3}{c}{ Pj Akar Total } & \multicolumn{3}{c}{ Luas Akar Total } \\
\cline { 2 - 10 } & $6 \mathrm{mst}$ & $9 \mathrm{mst}$ & Panen & $6 \mathrm{mst}$ & $9 \mathrm{mst}$ & Panen & $6 \mathrm{mst}$ & $9 \mathrm{mst}$ & Panen \\
\hline Cukup Air & $1,55 \mathrm{p}$ & $4,59 \mathrm{p}$ & $8,34 \mathrm{p}$ & $2299 \mathrm{p}$ & $6800 \mathrm{p}$ & $8636 \mathrm{p}$ & $570 \mathrm{p}$ & $1469 \mathrm{p}$ & $1884 \mathrm{p}$ \\
Kekeringan & $1,08 \mathrm{p}$ & $2,84 \mathrm{p}$ & $5,74 \mathrm{q}$ & $1505 \mathrm{p}$ & $4291 \mathrm{p}$ & $8104 \mathrm{p}$ & $358 \mathrm{p}$ & $885 \mathrm{p}$ & $1315 \mathrm{p}$ \\
\hline CV (\%) & 20,1 & 20,4 & 15,6 & 20,1 & 19 & 17,1 & 23,8 & 20,1 & 17,3 \\
\hline
\end{tabular}

Keterangan: Angka-angka diikuti oleh huruf sama pada kolom yang sama tidak berbeda nyata setelah dilakukan uji lanjut HSD Tukey dengan taraf kepercayaan 95\%. BK: Bobot Kering, Pj: Panjang, Luas: Luas Permukaan.

Berdasarkan Tabel 1 diketahui bahwa perakaran total antar kultivar pada seluruh variabel tidak ada perbedaan secara nyata pada 6 dan 9 mst, tetapi pada saat panen terjadi perbedaan antar kultivar. Kultivar Rindang 2 secara konsisten memiliki perakaran total yang paling besar walaupun tidak berbeda nyata dengan beberapa kultivar, kultivar Inpago 9 secara konsisten memiliki perakaran total yang paling kecil walaupun tidak berbeda nyata dengan beberapa kultivar.

Tabel 2 menggambarkan bahwa tidak ada perbedaan secara nyata perakaran total antar perlakuan kondisi lengas kecuali variabel bobot kering akar total pada saat panen, bobot kering akar total pada kondisi cukup air lebih besar dibandingkan dengan kondisi kekeringan.

Tabel 3. Nisbah Perakaran Dalam (Jumlah, Bobot Segar, dan Bobot Kering) pada 6, 9 mst, dan panen.

\begin{tabular}{llllllllll}
\hline \multirow{2}{*}{ Kultivar } & \multicolumn{3}{c}{ NPD JUMLAH } & \multicolumn{4}{c}{ NPD BS } & \multicolumn{3}{c}{ NPD BK } \\
\cline { 2 - 10 } & $6 \mathrm{mst}$ & $9 \mathrm{mst}$ & Panen & $6 \mathrm{mst}$ & $9 \mathrm{mst}$ & Panen & $6 \mathrm{mst}$ & $9 \mathrm{mst}$ & Panen \\
\hline Unsoed P. & $0,07 \mathrm{c}$ & $0,08 \mathrm{c}$ & $0,08 \mathrm{c}$ & $0,09 \mathrm{~b}$ & $0,05 \mathrm{c}$ & $0,04 \mathrm{c}$ & $0,09 \mathrm{~b}$ & $0,06 \mathrm{~b}$ & $0,04 \mathrm{c}$ \\
Rindang 2 & $0,44 \mathrm{a}$ & $0,35 \mathrm{a}$ & $0,31 \mathrm{a}$ & $0,46 \mathrm{a}$ & $0,38 \mathrm{a}$ & $0,22 \mathrm{a}$ & $0,46 \mathrm{a}$ & $0,38 \mathrm{a}$ & $0,21 \mathrm{a}$ \\
Inpago 9 & $0,12 \mathrm{bc}$ & $0,10 \mathrm{bc}$ & $0,09 \mathrm{bc}$ & $0,10 \mathrm{~b}$ & $0,07 \mathrm{bc}$ & $0,10 \mathrm{bc}$ & $0,10 \mathrm{~b}$ & $0,08 \mathrm{~b}$ & $0,08 \mathrm{bc}$ \\
Inpago 10 & $0,21 \mathrm{bc}$ & $0,15 \mathrm{~b}$ & $0,13 \mathrm{ab}$ & $0,17 \mathrm{~b}$ & $0,15 \mathrm{~b}$ & $0,17 \mathrm{ab}$ & $0,17 \mathrm{~b}$ & $0,16 \mathrm{ab}$ & $0,16 \mathrm{ab}$ \\
Inpago 11 & $0,13 \mathrm{bc}$ & $0,11 \mathrm{bc}$ & $0,10 \mathrm{c}$ & $0,13 \mathrm{~b}$ & $0,08 \mathrm{bc}$ & $0,06 \mathrm{c}$ & $0,14 \mathrm{~b}$ & $0,12 \mathrm{~b}$ & $0,08 \mathrm{bc}$ \\
IR64 & $0,26 \mathrm{~b}$ & $0,15 \mathrm{~b}$ & $0,17 \mathrm{ab}$ & $0,16 \mathrm{~b}$ & $0,14 \mathrm{bc}$ & $0,16 \mathrm{ab}$ & $0,16 \mathrm{~b}$ & $0,14 \mathrm{~b}$ & $0,24 \mathrm{a}$ \\
\hline CV (\%) & 6,9 & 16,21 & 11,95 & 10,66 & 23 & 15,64 & 15,4 & 23,15 & 22 \\
\hline K. Lengas & & & & & & & & & \\
Cukup Air & $0,25 \mathrm{p}$ & $0,16 \mathrm{p}$ & $0,15 \mathrm{p}$ & $0,19 \mathrm{p}$ & $0,15 \mathrm{p}$ & $0,12 \mathrm{p}$ & $0,19 \mathrm{p}$ & $0,16 \mathrm{p}$ & $0,14 \mathrm{p}$ \\
Kekeringan & $0,17 \mathrm{p}$ & $0,16 \mathrm{p}$ & $0,15 \mathrm{p}$ & $0,17 \mathrm{p}$ & $0,15 \mathrm{p}$ & $0,13 \mathrm{p}$ & $0,18 \mathrm{p}$ & $0,16 \mathrm{p}$ & $0,13 \mathrm{p}$ \\
\hline CV (\%) & 7,05 & 14,91 & 15,8 & 11,14 & 27 & 23,55 & 12,33 & 17,62 & 16,02 \\
\hline
\end{tabular}

Keterangan: Angka-angka yang diikuti oleh huruf yang sama pada kolom yang sama tidak berbeda nyata setelah dilakukan uji lanjut HSD Tukey dengan taraf kepercayaan 95\%. BS: Bobot Segar, BK: Bobot Kering.

Berdasarkan Tabel 3 dan 4 diketahui bahwa nisbah perakaran dalam antar kultivar pada seluruh variabel terdapat perbedaan secara nyata pada 6, 9 mst, dan panen. Kultivar Rindang 2 secara konsisten memiliki nisbah perakaran dalam yang paling besar dan berbeda nyata dengan beberapa kultivar, kultivar Unsoed Parimas secara konsisten memiliki nisbah perakaran dalam yang paling kecil walaupun tidak berbeda nyata dengan beberapa kultivar. Tidak ada perbedaan secara nyata nisbah perakaran dalam antar perlakuan kondisi lengas 
Tabel 4. Nisbah Perakaran Dalam (Panjang, Luas Permukaan, dan Volume) pada 6 dan 9 mst

\begin{tabular}{lllllll}
\hline \multirow{2}{*}{ Kultivar } & \multicolumn{2}{c}{ NPD PJ } & \multicolumn{2}{c}{ NPD LUAS } & \multicolumn{2}{c}{ NPD VOL } \\
\cline { 2 - 7 } & $9 \mathrm{mst}$ & Panen & $6 \mathrm{mst}$ & $9 \mathrm{mst}$ & $6 \mathrm{mst}$ & $9 \mathrm{mst}$ \\
\hline Unsoed P. & $0,07 \mathrm{~b}$ & $0,05 \mathrm{~b}$ & $0,09 \mathrm{~b}$ & $0,07 \mathrm{~b}$ & $0,09 \mathrm{~b}$ & $0,06 \mathrm{~b}$ \\
Rindang 2 & $0,40 \mathrm{a}$ & $0,18 \mathrm{a}$ & $0,54 \mathrm{a}$ & $0,42 \mathrm{a}$ & $0,55 \mathrm{a}$ & $0,45 \mathrm{a}$ \\
Inpago 9 & $0,09 \mathrm{~b}$ & $0,08 \mathrm{ab}$ & $0,12 \mathrm{~b}$ & $0,08 \mathrm{~b}$ & $0,11 \mathrm{~b}$ & $0,08 \mathrm{~b}$ \\
Inpago 10 & $0,17 \mathrm{ab}$ & $0,20 \mathrm{a}$ & $0,17 \mathrm{~b}$ & $0,16 \mathrm{ab}$ & $0,19 \mathrm{~b}$ & $0,16 \mathrm{~b}$ \\
Inpago 11 & $0,09 \mathrm{~b}$ & $0,04 \mathrm{~b}$ & $0,15 \mathrm{~b}$ & $0,08 \mathrm{~b}$ & $0,17 \mathrm{~b}$ & $0,08 \mathrm{~b}$ \\
IR64 & $0,15 \mathrm{~b}$ & $0,23 \mathrm{a}$ & $0,30 \mathrm{ab}$ & $0,16 \mathrm{~b}$ & $0,21 \mathrm{~b}$ & $0,18 \mathrm{~b}$ \\
\hline CV (\%) & 20,65 & 11,7 & 13,87 & 25 & 9,15 & 29 \\
\hline K. Lengas & & & & & & \\
Cukup Air & $0,16 \mathrm{p}$ & $0,14 \mathrm{p}$ & $0,26 \mathrm{p}$ & $0,17 \mathrm{p}$ & $0,26 \mathrm{p}$ & $0,17 \mathrm{p}$ \\
Kekeringan & $0,17 \mathrm{p}$ & $0,12 \mathrm{p}$ & $0,20 \mathrm{p}$ & $0,16 \mathrm{p}$ & $0,19 \mathrm{p}$ & $0,16 \mathrm{p}$ \\
\hline CV (\%) & 17,58 & 15,5 & 10,59 & 18 & 10,24 & 20,73 \\
\hline
\end{tabular}

Keterangan: Angka-angka yang diikuti oleh huruf yang sama pada kolom yang sama tidak berbeda nyata setelah dilakukan uji lanjut HSD Tukey dengan taraf kepercayaan 95\%. Pj: Panjang, Luas: Luas Permukaan, Vol: Volume.

Tabel 5. Nisbah Panjang Perakaran Dalam pada 6 mst

\begin{tabular}{llll}
\hline \multirow{2}{*}{ Kultivar } & \multicolumn{2}{c}{ Nisbah Panjang Perakaran Dalam } & \multirow{2}{*}{ Rerata } \\
\cline { 2 - 3 } & Cukup Air & Kekeringan & 0,08 \\
Unsoed Parimas & $0,09 \mathrm{~d}$ & $0,08 \mathrm{~d}$ & 0,54 \\
Rindang 2 & $0,68 \mathrm{a}$ & $0,40 \mathrm{abc}$ & 0,14 \\
Inpago 9 & $0,17 \mathrm{bcd}$ & $0,11 \mathrm{~cd}$ & 0,16 \\
Inpago 10 & $0,19 \mathrm{bcd}$ & $0,13 \mathrm{bcd}$ & 0,13 \\
Inpago 11 & $0,12 \mathrm{bcd}$ & $0,15 \mathrm{bcd}$ & 0,23 \\
IR64 & $0,41 \mathrm{ab}$ & $0,04 \mathrm{~d}$ & $(+)$ \\
\hline Rerata & 0,28 & 0,15 & \\
\hline CV (\%) & & 7,83 & \\
\hline
\end{tabular}

Keterangan: Angka-angka diikuti oleh huruf yang sama pada kolom yang sama, tidak berbeda nyata menurut uji lanjut HSD Tukey dengan taraf kepercayaan 95\%, (-): tidak ada interaksi. $\left(^{*}\right)$ data ditransformasi dalam bentuk square root.

Tabel 5. menunjukkan nilai nisbah panjang perakaran dalam pada saat 6 mst. Terjadi interaksi antara kultivar dengan kondisi lengas tanah. Kekeringan tidak merubah nisbah panjang perakaran dalam semua kultivar yang diteliti, kecuali IR 64. Kultivar IR 64 mengalami penurunan nisbah panjang perakaran dalam bila mengalami kekeringan. Pada kondisi cukup air, nisbah panjang perakaran dalam kultivar Rindang 2 tertinggi walaupun tidak berbeda nyata dengan kultivar IR 64. Pada kondisi kering nilai nisbah panjang perakaran dalam IR 64 dan Unsoed Parimas terendah, walaupun tidak berbeda nyata dengan kultivar yang lain dengan kultivar yang lain, kecuali Rindang 2 yang mempunyai nilai tertinggi.

Tabel 6. menunjukkan nilai nisbah luas permukaan perakaran dalam pada saat panen. Terjadi interaksi antara kultivar dengan kondisi lengas tanah. Secara umum, nisbah luas permukaan perakaran dalam saat panen tidak terjadi perubahan secara nyata. Kekeringan tidak merubah nisbah luas permukaan akar semua kultivar yang diteliti, kecuali IR 64 . Kultivar IR 64 mengalami penurunan nisbah luas permukaan perakaran dalam bila mengalami kekeringan. Pada kondisi cukup air, nisbah luas permukaan perakaran dalam kultivar IR 64 
tertinggi walaupun tidak berbeda nyata dengan kultivar Rindang 2, Inpago 9 dan Inpago 10. Pada kondisi kering nilai nisbah luas permukaan perakaran dalam IR 64 terendah, walaupun tidak berbeda nyata dengan kultivar yang lain kecuali Inpago 10 yang mempunyai nilai tertinggi.
Perbedaan ini dikarenakan setiap kultivar memiliki distribusi akar yang berbeda-beda sehingga nilai nisbah luas permukaan perakaran dalam tidak sama antar kultivar dan antar perlakuan kondisi lengas tanah.

Tabel 6. Nisbah Luas Permukaan Perakaran Dalam saat Panen

\begin{tabular}{|c|c|c|c|}
\hline \multirow{2}{*}{ Kultivar } & \multicolumn{2}{|c|}{ Nisbah Luas Permukaan Perakaran Dalam* } & \multirow{2}{*}{ Rerata } \\
\hline & Cukup Air & Kekeringan & \\
\hline Unsoed Parimas & $0,04 \mathrm{~b}$ & $0,11 a b$ & 0,07 \\
\hline Rindang 2 & $0,15 a b$ & $0,20 a b$ & 0,17 \\
\hline Inpago 9 & $0,11 a b$ & $0,05 \mathrm{~b}$ & 0,08 \\
\hline Inpago 10 & $0,15 a b$ & $0,36 \mathrm{a}$ & 0,25 \\
\hline Inpago 11 & $0,03 \mathrm{~b}$ & $0,04 \mathrm{~b}$ & 0,04 \\
\hline IR64 & $0,38 \mathrm{a}$ & $0,04 \mathrm{~b}$ & 0,21 \\
\hline Rerata & 0,14 & 0,13 & $(+)$ \\
\hline
\end{tabular}

Keterangan: Angka-angka diikuti oleh huruf yang sama pada kolom yang sama, tidak berbeda nyata menurut uji lanjut HSD Tukey dengan taraf kepercayaan 95\%, (-): tidak ada interaksi. ( $\left.{ }^{*}\right)$ data ditransformasi dalam bentuk square root.

Tabel 7. Nisbah Volume Perakaran Dalam saat Panen

\begin{tabular}{llll}
\hline \multirow{2}{*}{ Kultivar } & \multicolumn{2}{c}{ Nisbah Volume Perakaran Dalam ${ }^{*}$} & \multirow{2}{*}{ Rerata } \\
\cline { 2 - 3 } & Cukup Air & Kekeringan & 0,11 \\
\cline { 1 - 3 } Unsoed Parimas & $0,06 \mathrm{abc}$ & $0,16 \mathrm{abc}$ & 0,18 \\
Rindang 2 & $0,15 \mathrm{abc}$ & $0,20 \mathrm{abc}$ & 0,08 \\
Inpago 9 & $0,12 \mathrm{abc}$ & $0,04 \mathrm{bc}$ & 0,3 \\
Inpago 10 & $0,14 \mathrm{abc}$ & $0,47 \mathrm{ab}$ & 0,04 \\
Inpago 11 & $0,03 \mathrm{c}$ & $0,04 \mathrm{bc}$ & 0,21 \\
IR64 & $0,40 \mathrm{a}$ & $0,03 \mathrm{c}$ & $(+)$ \\
\hline Rerata & 0,15 & 0,16 & \\
\hline
\end{tabular}

CV $(\%)$

9,47

Keterangan: Angka-angka diikuti oleh huruf yang sama pada kolom yang sama, tidak berbeda nyata menurut uji lanjut HSD Tukey dengan taraf kepercayaan 95\%, (-): tidak ada interaksi. ( $\left.{ }^{*}\right)$ data ditransformasi dalam bentuk square root.

Tabel 7 menunjukkan nilai nisbah volume perakaran dalam pada saat panen. Terjadi interaksi antara kultivar dengan kondisi lengas tanah. Kekeringan tidak merubah nisbah luas permukaan akar semua kultivar yang diteliti, kecuali IR 64. Kultivar IR 64 mengalami penurunan nisbah luas permukaan perakaran dalam bila mengalami kekeringan. Pada kondisi cukup air, nisbah luas permukaan perakaran dalam kultivar IR 64 tertinggi walaupun tidak berbeda nyata dengan kultivar Unsoed Parimas, Rindang 2, Inpago 9, dan Inpago 10. Pada 
kondisi kering nilai nisbah luas permukaan perakaran dalam IR 64 terendah, walaupun tidak berbeda nyata dengan kultivar yang lain kecuali Inpago 10 yang mempunyai nilai tertinggi.

Indikator yang dapat digunakan untuk mengetahui tingkat ketahanan suatu kultivar terhadap cekaman kekeringan yaitu dengan menghitung nilai indeks toleransi cekaman (ITC) dari bagian total tanaman dan hasil tanaman untuk padi berupa gabah (biji). Menurut
Fernandez (1992) dalam Effendi dan Azrai (2015), bahwa kriteria untuk menentukan tingkat toleransi suatu tanaman terhadap cekaman kekeringan adalah jika diperoleh nilai ITC $\leq 0,5$ maka kultivar tersebut tergolong peka, jika nilai yang diperoleh $0,5 \leq \mathrm{ITC} \leq 1,0$ maka kultivar tersebut tergolong medium toleran, sedangkan jika nilai ITC > 1,0 maka kultivar tersebut tergolong toleran.

Tabel 8. Indeks Toleransi Cekaman (ITC) Bobot Kering Tanaman dan Hasil

\begin{tabular}{lllll}
\hline \multirow{2}{*}{ Kultivar } & \multicolumn{3}{c}{ ITC Tanaman } & \multirow{2}{*}{ ITC Hasil* } \\
\cline { 2 - 4 } & $6 \mathrm{mst}$ & $9 \mathrm{mst}$ & Panen & $0,2137 \mathrm{ab}$ \\
Unsoed Parimas & $0,5092 \mathrm{a}$ & $0,4251 \mathrm{a}$ & $0,4461 \mathrm{a}$ & $0,2202 \mathrm{ab}$ \\
Rindang 2 & $0,8142 \mathrm{a}$ & $0,4877 \mathrm{a}$ & $0,4584 \mathrm{a}$ & $0,1771 \mathrm{~b}$ \\
Inpago 9 & $0,6880 \mathrm{a}$ & $0,4901 \mathrm{a}$ & $0,3712 \mathrm{a}$ & $0,2271 \mathrm{ab}$ \\
Inpago 10 & $0,6611 \mathrm{a}$ & $0,5029 \mathrm{a}$ & $0,6091 \mathrm{a}$ & $0,2126 \mathrm{ab}$ \\
Inpago 11 & $0,9065 \mathrm{a}$ & $0,5104 \mathrm{a}$ & $0,5996 \mathrm{a}$ & $0,6145 \mathrm{a}$ \\
IR64 & $0,8599 \mathrm{a}$ & $0,5903 \mathrm{a}$ & $0,4381 \mathrm{a}$ & 10,34 \\
\hline CV (\%) & 22,59 & 21,38 & 25,60 & .
\end{tabular}

Keterangan: Angka-angka diikuti oleh huruf yang sama pada kolom yang sama, tidak berbeda nyata menurut uji HSD Tukey dengan taraf kepercayaan 95\%. $\left(^{*}\right)$ menunjukkan data ditransformasi dalam bentuk square root.

Nilai Indeks Toleransi Cekaman yang diperoleh dari bobot kering tanaman pada $6 \mathrm{mst}$, 9 mst, dan panen tidak berbeda nyata menurut statistik, akan tetapi jika ditinjau dari kriteria indeks toleransi cekaman maka tingkat toleransi antar kultivar berbeda. Pada 6 mst, semua kultivar termasuk golongan tanaman yang medium toleran cekaman. Pada 9 mst, kultivar Unsoed Parimas, Rindang 2, dan Inpago 9 termasuk ke dalam golongan tanaman yang peka cekaman, sedangkan kultivar Inpago 10, Inpago 11, dan IR64 termasuk ke dalam golongan tanaman yang medium toleran cekaman. Pada saat panen, kultivar Unsoed Parimas, Rindang 2, Inpago 9, dan IR64 termasuk ke dalam golongan tanaman yang peka cekaman, sedangkan kultivar Inpago 10 dan Inpago 11 termasuk ke dalam golongan tanaman yang medium toleran cekaman. Tanggapan tanaman padi terhadap cekaman kekeringan bergantung pada tingkat keparahan kekeringan, waktu (fase tumbuh) terjadinya kekeringan (Kadir, 2011), dan genotipe (Castillo et al., 2006). Berdasarkan nilai Indeks Toleransi Cekaman yang diperoleh dari hasil (gabah) terdapat beda nyata antar beberapa kultivar. Kultivar IR64 memiliki nilai Indeks Toleransi Cekaman tertinggi dan berbeda nyata dengan kultivar Inpago 9. Kultivar Unsoed Parimas, Rindang 2, Inpago 9, Inpago 10, dan Inpago 11 termasuk ke dalam golongan tanaman yang peka cekaman, sedangkan kultivar IR64 termasuk ke dalam golongan tanaman yang medium toleran cekaman. 
Tabel 9. Bobot Gabah Kering saat Panen

\begin{tabular}{|c|c|c|c|}
\hline \multirow[b]{2}{*}{ Kultivar } & \multicolumn{2}{|c|}{ Bobot Gabah Kering } & \multirow[b]{2}{*}{ Rerata } \\
\hline & Cukup Air & Kekeringan & \\
\hline Unsoed Parimas & $54,27 a$ & $11.48 \mathrm{bcd}$ & 32,87 \\
\hline Rindang 2 & $50,94 \mathrm{a}$ & $11.38 \mathrm{bcd}$ & 31,16 \\
\hline Inpago 9 & $28,79 a b$ & $5.090 \mathrm{~d}$ & 16,94 \\
\hline Inpago 10 & $21,88 \mathrm{bc}$ & $5.080 \mathrm{~d}$ & 13,48 \\
\hline Inpago 11 & $26,74 a b$ & $5.800 \mathrm{~cd}$ & 16,27 \\
\hline IR64 & $23,42 b$ & $16.68 \mathrm{bcd}$ & 20,05 \\
\hline Rerata & 34,34 & 9,25 & $(+)$ \\
\hline CV (\%) & 20,9 & & \\
\hline
\end{tabular}

Keterangan: Angka-angka diikuti oleh huruf yang sama pada kolom yang sama, tidak berbeda nyata menurut uji lanjut HSD Tukey dengan taraf kepercayaan 95\%, (-): tidak ada interaksi. $\left(^{*}\right)$ data ditransformasi dalam bentuk square root.

Komponen hasil berupa bobot gabah nyata dengan kultivar Inpago 9 dan 11. Pada kering ditampilkan pada tabel 2. Terjadi interaksi kondisi kering bobot gabah kering Inpago 9 dan antara kultivar dengan kondisi lengas tanah. 10 terendah, walaupun tidak berbeda nyata Kekeringan merubah bobot gabah kering semua dengan kultivar yang lain. Kultivar yang kultivar yang diteliti, kecuali IR 64. Kultivar IR 64 mengalami penurunan hasil secara drastis pada tidak mengalami penurunan bobot gabah kering kondisi kekeringan memiliki nilai indeks toleransi bila mengalami kekeringan. Pada kondisi cukup cekaman yang rendah, dan sebaliknya. air, bobot gabah kering kultivar Unsoed Parimas dan Rindang 2 tertinggi walaupun tidak berbeda

Tabel 10. Korelasi Nisbah Perakaran Dalam dengan Indeks Toleransi Cekaman (ITC) pada 6 mst.

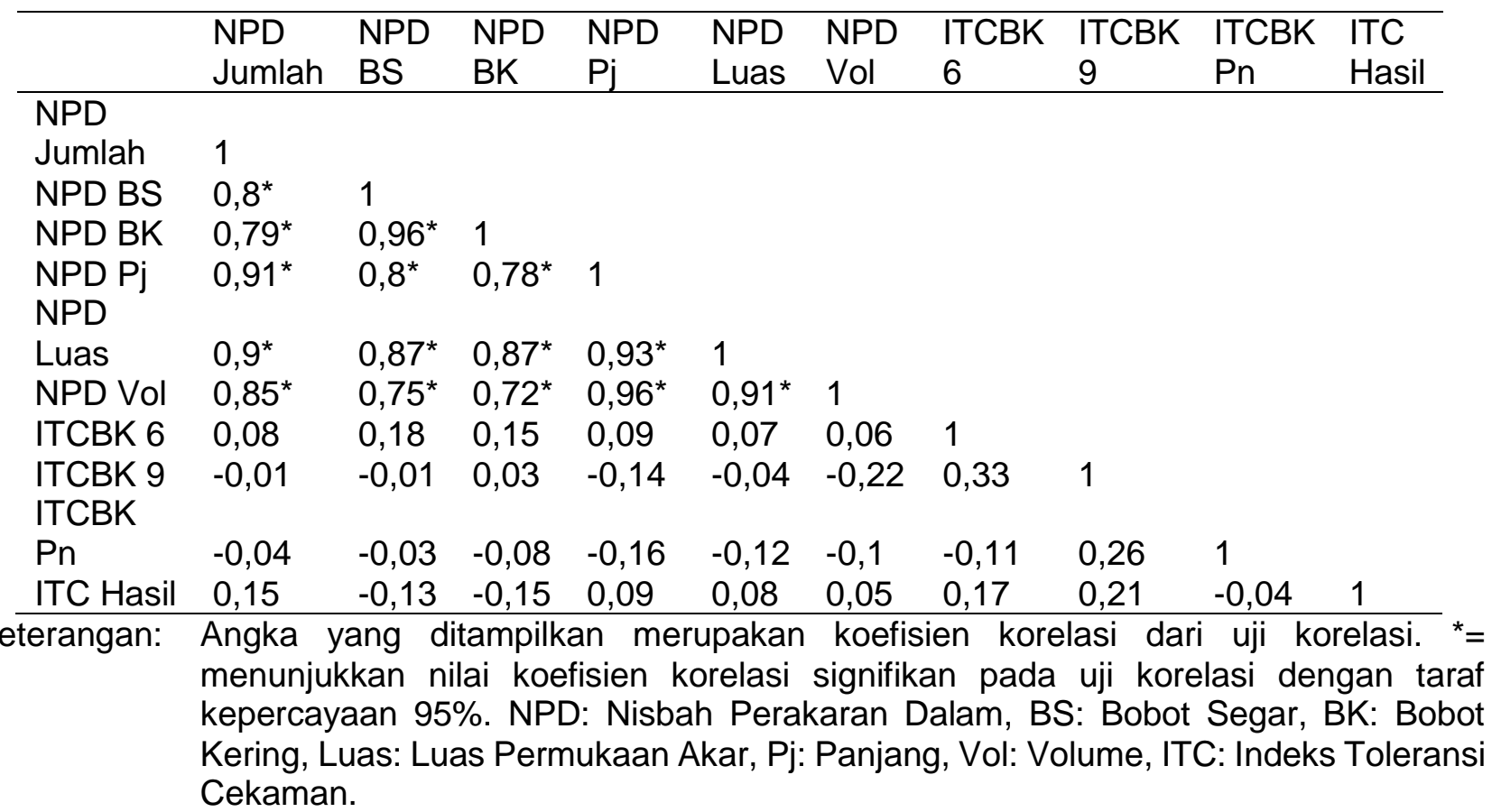


Tabel 11. Korelasi Nisbah Perakaran Dalam dengan Indeks Toleransi Cekaman (ITC) pada 9 mst.

\begin{tabular}{llllllllll}
\hline & $\begin{array}{l}\text { NPD } \\
\text { Jumlah }\end{array}$ & $\begin{array}{l}\text { NPD } \\
\text { BS }\end{array}$ & $\begin{array}{l}\text { NPD } \\
\text { BK }\end{array}$ & NPD Pj & $\begin{array}{l}\text { NPD } \\
\text { Luas }\end{array}$ & $\begin{array}{l}\text { NPD } \\
\text { Vol }\end{array}$ & $\begin{array}{l}\text { ITCBK } \\
9\end{array}$ & $\begin{array}{l}\text { ITCBK } \\
\text { Pn }\end{array}$ & $\begin{array}{l}\text { ITC } \\
\text { Hasil }\end{array}$ \\
\hline NPD Jumlah & 1 & & & & & & & & \\
NPD BS & $0,94^{*}$ & 1 & & & & & & & \\
NPD BK & $0,94^{*}$ & $0,99^{*}$ & 1 & & & & & & \\
NPD Pj & $0,91^{*}$ & $0,98^{*}$ & 0,98 & 1 & & & & & \\
NPD Luas & $0,91^{*}$ & $0,96^{*}$ & $0,96^{*}$ & $0,99^{*}$ & 1 & & & & \\
NPD Vol & $0,89^{*}$ & $0,93^{*}$ & $0,94^{*}$ & $0,97^{*}$ & $0,99^{*}$ & 1 & & & \\
ITCBK 9 & $-0,02$ & $-0,04$ & 0,02 & 0,04 & 0,06 & 0,08 & 1 & & \\
ITCBK Pn & 0,01 & $-0,08$ & $-0,03$ & $-0,04$ & 0 & 0,02 & 0,26 & 1 & \\
ITC Hasil & 0,05 & 0,1 & 0,11 & 0,07 & 0,12 & 0,16 & 0,21 & $-0,04$ & 1 \\
\hline
\end{tabular}

Keterangan: Angka yang ditampilkan merupakan koefisien korelasi dari uji korelasi. ${ }^{*}=$ menunjukkan nilai koefisien korelasi signifikan pada uji korelasi dengan taraf kepercayaan 95\%. NPD: Nisbah Perakaran Dalam, BS: Bobot Segar, BK: Bobot Kering, Luas: Luas Permukaan Akar, Pj: Panjang, Vol: Volume, ITC: Indeks Toleransi Cekaman.

Defisit air dalam jangka waktu yang pendek hanya berpengaruh pada kapasitas pertukaran gas dan efisiensi fotosintesis, sedangkan untuk jangka panjang mengakibatkan menurunnya efisiensi pembentukan bahan kering (Munchow et al., 1986). Kekurangan air mengakibatkan berkurangnya laju fotosintesis karena dehidrasi protoplas akan menurunkan kapasitas fotosintesis (Thomas dan Lasminingsih, 1994). Rendahnya jumlah air akan menyebabkan terbatasnya perkembangan akar, sehingga mengganggu penyerapan unsur hara oleh akar tanaman (Santosa, 1995). Karakter ketahanan terhadap cekaman merupakan sifat yang menunjukkan kemampuan tanaman untuk bertahan hidup dan berproduksi pada kondisi maupun lingkungan yang tercekam. Pada umumnya tanaman yang mengalami cekaman kekeringan akan mengalami penurunan hasil, tingkat penurunan hasil masing-masing kultivar tanaman akan berbeda-beda tergantung pada kemampuan dari adaptasi dari setiap tanaman dalam kondisi cekaman (Efendi dan Azrai, 2015). Tingkat ketahanan suatu kultivar pada lingkungan tercekam kekeringan dapat ditentukan berdasarkan nilai indeks cekaman yang dihitung berdasarkan perbandingkan hasil pada kondisi cekaman dan normal (cukup air).

Tabel 10 menunjukkan bahwa pada 6 mst terdapat korelasi antar variabel nisbah perakaran dalam, namun tidak terdapat korelasi antara variabel nisbah perakaran dalam dengan indeks toletansi cekaman bobot kering pada semua umur maupun indeks toletansi cekaman hasil. Tabel 11 menunjukkan bahwa pada 9 mst terdapat korelasi antar variabel nisbah perakaran dalam, namun tidak terdapat korelasi antara variabel nisbah perakaran dalam dengan indeks toletansi cekaman bobot kering pada semua umur maupun indeks toletansi cekaman hasil.

Korelasi antara nisbah perakaran dalam dengan indeks toleransi cekaman saat panen dicantumkan dalam Tabel 12. Tabel tersebut menunjukkan bahwa terdapat korelasi antar variabel nisbah perakaran dalam, tidak terdapat korelasi antara nisbah perakaran dalam dengan indeks toleransi cekaman bobot kering. namun terdapat korelasi antara sebagian variabel nisbah perakaran dalam dengan indeks toleransi cekaman hasil. Lebih rinci Tabel 7 menunjukkan bahwa nisbah perakaran dalam jumlah tidak mempunyai korelasi dengan indeks toleransi 
cekaman hasil, namun terdapat korelasi nisbah perakaran dalam bobot kering, panjang dan luas dengan indeks toleransi cekaman hasil. Korelasi yang diperoleh dari ITC hasil (gabah) merupakan karakter yang sangat penting karena korelasi langsung ditunjukkan melalui hasil tanaman (gabah) sebagai tolok ukur keberhasilan produksi tanaman yang mengalami kondisi kekeringan. Apabila uji korelasi antara seluruh variabel pengamatan nisbah perakaran dalam dengan nilai ITC hasil (gabah) tidak memberikan angka yang berbeda nyata maka nisbah perakaran dalam tidak memiliki keterkaitan dan pengaruh nyata terhadap ketahanan kekeringan dan hasil beberapa kultivar pada kondisi cekaman kekeringan, walaupun ada hubungan antara nisbah perakaran dalam (bobot kering, panjang, luas permukaan) dengan ITC Hasil.

Tabel 12. Korelasi Nisbah Perakaran Dalam dengan Indeks Toleransi Cekaman (ITC) pada saat panen.

\begin{tabular}{|c|c|c|c|c|c|c|c|c|}
\hline & $\begin{array}{l}\text { NPD } \\
\text { Jumlah }\end{array}$ & $\begin{array}{l}\text { NPD } \\
\text { BS }\end{array}$ & $\begin{array}{l}\text { NPD } \\
\text { BK }\end{array}$ & NPD Pj & $\begin{array}{l}\text { NPD } \\
\text { Luas }\end{array}$ & $\begin{array}{l}\text { NPD } \\
\text { Vol }\end{array}$ & $\begin{array}{l}\text { ITCBK } \\
\mathrm{Pn}\end{array}$ & $\begin{array}{l}\text { ITC } \\
\text { Hasil }\end{array}$ \\
\hline NPD Jumlah & 1 & & & & & & & \\
\hline NPD BS & $0,76^{*}$ & 1 & & & & & & \\
\hline NPD BK & $0,57^{*}$ & $0,78^{*}$ & 1 & & & & & \\
\hline NPD $\mathrm{Pj}$ & $0,45^{*}$ & $0,79^{\star}$ & $0,92^{*}$ & 1 & & & & \\
\hline NPD Luas & 0,36 & $0,75^{*}$ & $0,82^{*}$ & $0,94^{*}$ & 1 & & & \\
\hline NPD Vol & 0,29 & $0,67^{*}$ & $0,69^{*}$ & $0,84^{*}$ & $0,97^{\star}$ & 1 & & \\
\hline ITCBK Pn & 0 & $-0,02$ & $-0,13$ & $-0,02$ & 0,05 & 0,1 & 1 & \\
\hline ITC Hasil & 0,2 & 0,22 & $0,54^{*}$ & $0,57^{*}$ & $0,46^{*}$ & 0,35 & $-0,04$ & 1 \\
\hline rangan: & $\begin{array}{l}\text { a yan } \\
\text { injukka } \\
\text { cayaar } \\
\text { g, Luas } \\
\text { man. }\end{array}$ & $\begin{array}{l}\text { ditamp } \\
\text { nilai } k \\
95 \% . \\
\text {-uas } P \epsilon\end{array}$ & $\mathrm{an} m \epsilon$ & pakan & efisien & $\begin{array}{l}\text { orelasi } \\
\text { da uji } \\
\text { BS: } \\
\text { Volum }\end{array}$ & $\begin{array}{l}\text { lari uji } \\
\text { orelasi } \\
\text { ot Seg } \\
\text { ITC: Inc }\end{array}$ & $\mathrm{ks} 7$ \\
\hline
\end{tabular}

Berdasarkan uji korelasi yang dilakukan pada saat 6 mst dan 9 mst dapat diketahui bahwa tidak ada hubungan antara seluruh variabel nisbah perakaran dalam dengan indeks toleransi cekaman yang diperoleh dari bobot kering maupun hasil tanaman. Hal tersebut menunjukkan bahwa dengan medium tanah, nisbah perakaran dalam tidak dapat digunakan sebagai indikator untuk pendugaan ketahanan kekeringan tanaman padi secara dini. Perakaran yang tumbuh ke dalam tidak selalu menjadi sifat perakaran yang dapat dijadikan sebagai indikator suatu tanaman yang tahan terhadap kondisi kekeringan dikarenakan tanaman kemungkinan memodifikasi morfologi dan distribusi sistem perakarannya untuk tumbuh menyebar ke samping pada permukaan tanah untuk dapat mempertahankan diri dari cekaman kekeringan tanpa harus memperluas distribusi perakaran ke arah bagian bawah lapisan tanah 


\section{KESIMPULAN}

1. Nisbah perakaran dalam (bobot kering, panjang, luas) saat panen mempunyai hubungan nyata positif dengan indeks toleransi cekaman hasil.

2. Dengan menggunakan medium tanah, nisbah perakaran dalam tidak dapat digunakan untuk melakukan pendugaan ketahanan kekeringan tanaman padi

\section{DAFTAR PUSTAKA}

Abdullah, A. A., M. H. Ammar, and A. T. Badawi. 2010. Screening rice genotypes for drought resistance in Egypt. Journal of Plant Breeding and Crop Science 2(7):205-215.

Castillo, E.G., T.P. Tuong, U. Singh, K. Inubushi, and J. Padilla. 2006. Drought response of dry seeded rice to water stress timing, $\mathrm{N}$ fertilizer rates and sources. Soil Sci. Plant Nutr. 52:249-508.

Comas, L.H., Becker, S.R., Cruz, V.M.V., Byrne, P.F. and Dierig, D.A. 2013. Root traits contributing to plant productivity under drought. Frontiers in Plant Science 4 (442): 1-16.

Efendi, R., dan Azrai, M. 2015. Kriteria indeks toleran jagung terhadap cekaman kekeringan dan nitrogen rendah. In Prosiding Seminar Nasional Serealia 2015:1-12.

Kadir, A. 2011. Respon genotipe padi mutan hasil iradiasi sinar gamma terhadap cekaman kekeringan. Jurnal Agrivivor 10(3):235-246.
Mackill, D.J., W.R. Coffman and D.P. Garrity. 1996. Rainfed Lowland Rice Improvement. IRRI. Manila.

Munchow, R.C., T.R. Sinclair, J.M. Benneth and L.C. Hammond. 1986. Respons of leaf growth, leaf nitrogen and stomatal conductance on water deficit during vegetation growth of field growth soybean. Crop. Sci. 26:1190-1195.

Purwono dan Purwanti, H. 2007. Budidaya Delapan Jenis Tanaman Pangan Unggul. Penebar Swadaya. Jakarta.

Rathnayake, W.M.U.K., De Silva R.P., and Dayawansa N.D.K. 2016. Assessment of the suitability of temperature and relative humidity for rice cultivation in rainfed lowland paddy fields in Kurunegala district. Tropical Agricultural Research 27(4):370-388.

Reyes, BG., De Los, Myers SJ., and McGrath JM. 2003. Differential induction of glyoxylate cycle enzymes by stress as a marker for seedling vigor in sugar beet (Beta vulgaris). Molecular Genetics and Genomics 269(5): 692-698.

Tao, H., H. Brueck, K. Dittert, C. Kreye, S. Lin, and B. Sattelmacher. 2006. Growth and yield formation for rice (Oryza sativa L.) in the water-saving ground cover rice production system (GCRPS). Field Crops Research 95(1):1-12. 
Thomas dan Muji Lasminingsih. 1994. Respons beberapa klon karet terhadap kekeringan. Buletin Perkaretan. 12(3): 1-4.

Uga, Y., K. Okuno and M, Yano. 2011. Dro1, a major QTL involved in deep rooting of rice under upland field conditions. Journal of Experimental Botany 62(8):1-10.
Vijayakumar, CHM. 1996. Hybrid rice seed production technology-theory and practice. Directorate of Rice Research, Hyderabad. 